\title{
Effect of Aggregate Volume Fraction on the Elastic Moduli and Void Ratio of Cement-Based
}

Shih-Wei Cho

Ph.D. Candidate, Institute of Materials Engineering, National Taiwan Ocean University, Keelung, Taiwan, R.O.C.

Chung-Chia Yang

Professor, Institute of Materials Engineering, National Taiwan Ocean University, Keelung, Taiwan, R.O.C.

Ran Huang

Professor, Department of Harbor and River Engineering, National Taiwan Ocean University, Keelung, Taiwan, R.O.C.

Follow this and additional works at: https://jmstt.ntou.edu.tw/journal

Part of the Mechanical Engineering Commons

\section{Recommended Citation}

Cho, Shih-Wei; Yang, Chung-Chia; and Huang, Ran (2000) "Effect of Aggregate Volume Fraction on the Elastic Moduli and Void Ratio of Cement-Based," Journal of Marine Science and Technology: Vol. 8: Iss. 1, Article 1.

DOI: $10.51400 / 2709-6998.2448$

Available at: https://jmstt.ntou.edu.tw/journal/vol8/iss1/1

This Research Article is brought to you for free and open access by Journal of Marine Science and Technology. It has been accepted for inclusion in Journal of Marine Science and Technology by an authorized editor of Journal of Marine Science and Technology. 
Effect of Aggregate Volume Fraction on the Elastic Moduli and Void Ratio of Cement-Based

Acknowledgements

The support of NSC Contract No. NSC 88-2221-E019-007 is gratefully appreciated.

This research article is available in Journal of Marine Science and Technology: https://jmstt.ntou.edu.tw/journal/vol8/ 


\title{
EFFECT OF AGGREGATE VOLUME FRACTION ON THE ELASTIC MODULI AND VOID RATIO OF CEMENT-BASED MATERIALS
}

\author{
Shih-Wei Cho*, Chung-Chia Yang ${ }^{* *}$, and Ran Huang ${ }^{* * *}$
}

Keywords: Void, Elastic moduli, Fine aggregate, Double inclusion.

\section{ABSTRACT}

The effects of aggregate volume fraction on the void ratio and the elastic modulus of mortar were studied. Cylindrical specimens with six volume fractions $(a / t=0 ., 0.05,0.1,0.2,0.3$, and 0.4$)$ of fine aggregate and various water/cement ratios $(w / c=0.3,0.4$, and 0.5$)$ were cast and tested. Double inclusion model for three-phase composite (matrix, aggregate, and void) was used to predict the volume of total void based on the properties and quantities of the components and composites. Based on this study, when higher volume fraction of aggregate is used in the mix, the elastic modulus of the composite should be computed by introducing a third phase (void) into the composite. For the mix with lower volume fraction of aggregate, because the volume of void is relatively small in comparison with the volume of other components, two-phase approach is appropriate for evaluating the elastic moduli of the composites.

\section{INTRODUCTION}

Cement-based materials contains air voids, capillary voids, and interlayer space in C-S-H. Air void have diameter usually larger than a few micrometers which includes both entrapped and entrained voids. Capillary voids represent the space not filled by the hydrated cement paste. The void size associated in the C-S-H structure is too small to have an adverse effect on the strength and permeability of the hydrated cement paste [1].

Portland cement-based material is a multiphase and porous material. Prediction of the elastic moduli of cement based materials is complicated by the heterogeneous microstructure. The properties of cement-based materials are influenced by the volume fraction of the

Paper Received July 14, 1999. Author for Correspondence: C. C. Yang. *Ph.D. Candidate, Institute of Materials Engineering, National Taiwan Ocean University, Keelung, Taiwan, R.O.C.

**Professor, Institute of Materials Engineering, National Taiwan Ocean University, Keelung, Taiwan, R.O.C.

***Professor, Department of Harbor and River Engineering, National Taiwan Ocean University, Keelung, Taiwan, R.O.C. components (cement paste and fine aggregate). In addition, considering the matrix with micropores, the study of cement-based materials becomes more complex and the cement-based materials are usually considered as a three-phase composite which consists of buck cement paste, aggregate, and void, and each phase has its own elastic modulus.

Manning and Hope [2] investigated the influence of porosity on the elastic modulus of polymer impregnated concrete. Hasselman et al. [3] reported that pore shape is an important factor affecting the elastic behavior of polymer-impregnated porous ceramics. Beandoin et al. [4] presented a critical literature review on the pore structure effects. Zimmerman et al. [5] investigated the influence of porosity on the elastic moduli of mortar and comparing their experimental results with theoretical result.

Hirsch [6] pointed out that the elastic modulus of cement paste is influenced by the water/cement ratio and the age of cement paste and also derived an equation to express the elastic modulus of mortar and concrete using an empirical constant. By considering concrete as a two-phase material, Aitcin and Mehta [7], Baalbaki et al. [8] demonstrated that the elastic modulus of concrete was influenced by the elastic properties and volume fraction of aggregates. Stock et al. [9] also obtained some experimental results for the elastic moduli of mortar and concrete with different aggregate volume fractions. In the past, the overall mechanical behavior of composite materials has been extensively studied. Voigt's [10] approximation yielded the parallel model and the Reuss's [11] approximation yielded the series model of the average elastic moduli. Hashin and Shtrikman [12] proposed the variational principle to find bounds on the average elastic moduli of composite materials which were superior to the Voigt and Reuss models. Hansen [13] developed a mathematical models to predict the elastic moduli of composite materials based on the individual elastic modulus and volume fraction of the components. Mori and Tanaka [14] applied the concept of average field to analyze macroscopic properties of composite materials. The average 
Table 1. Mix design and volume fraction of aggregate

\begin{tabular}{ccccccr}
\hline Notation & $\begin{array}{c}\mathrm{w} / \mathrm{c} \\
\left(\mathrm{kg} / \mathrm{m}^{3}\right)\end{array}$ & $\begin{array}{c}\text { Water } \\
\left(\mathrm{kg} / \mathrm{m}^{3}\right)\end{array}$ & $\begin{array}{c}\text { Cement } \\
\left(\mathrm{kg} / \mathrm{m}^{3}\right)\end{array}$ & $\begin{array}{c}\mathrm{SP} \\
\left(\mathrm{kg} / \mathrm{m}^{3}\right)\end{array}$ & $\begin{array}{c}\text { Aggregate } \\
\text { ratio, }(\%)\end{array}$ & *Volume \\
\hline A00 & & 461.6 & 1591.6 & 15.9 & 0 & 0 \\
A05 & & 438.0 & 1510.4 & 15.1 & 129.7 & 5 \\
A10 & 0.3 & 414.5 & 1429.2 & 14.3 & 259.3 & 10 \\
A20 & & 367.4 & 1266.8 & 12.7 & 518.6 & 20 \\
A30 & & 320.3 & 1104.4 & 11.0 & 777.9 & 30 \\
A40 & & 273.2 & 941.9 & 9.4 & 1037.2 & 40 \\
B00 & & 540.2 & 1367.6 & 6.8 & 0 & 0 \\
B05 & 512.6 & 1297.8 & 6.5 & 129.7 & 5 \\
B10 & 0.4 & 485.1 & 1228.0 & 6.1 & 259.3 & 10 \\
B20 & & 430.0 & 1088.5 & 5.4 & 518.6 & 20 \\
B30 & & 374.8 & 949.0 & 4.7 & 777.9 & 30 \\
B40 & & 319.7 & 809.4 & 4.0 & 1037.2 & 40 \\
C00 & & 599.4 & 1198.8 & 0 & 0 & 0 \\
C05 & & 568.8 & 1137.7 & 0 & 129.7 & 5 \\
C10 & 0.5 & 538.3 & 1076.5 & 0 & 259.3 & 10 \\
C20 & & 477.1 & 954.2 & 0 & 518.6 & 20 \\
C30 & & 415.9 & 831.8 & 0 & 777.9 & 30 \\
C40 & & 354.8 & 709.5 & 0 & 1037.2 & 40 \\
\hline
\end{tabular}

*(the volume of sand)/(the volume of mortar)

field in a body contains inclusions with eigenstrain. In addition, the shape effect of dispersoids was introduced in Eshelby's [15] method to assess the properties of composite materials. The recent development of evaluating overall elastic modulus and overall elastic-plastic behavior was reviewed by Mura [16].

In this study, the elastic moduli of cement paste and mortars were obtained in the laboratory. The estimated elastic modulus of the fine aggregate was calculated by single inclusion model [17] for the mortar with a w/c ratio of 0.3 . Yang and Huang's double inclusion model [18] for three-phase composite (matrix, aggregate, and total void) was used to predict the volume fraction of void (air voids, capillary voids, and the voids within interlayer space in $\mathrm{C}-\mathrm{S}-\mathrm{H}$ ) for the mortar with various $\mathrm{w} / \mathrm{c}$ ratios and fine aggregate volume fractions.

\section{EXPERIMENTAL PROGRAM}

In this study, the mortar was composed of cement paste, fine aggregate, and void. Mortars were made with ordinary Type I cement, and fine aggregate. The fine aggregate (sieve size between \#16 and \#30) was used. The proportions of the mortar are summarized in Table 1; three different mortars, $\mathrm{A}, \mathrm{B}$, and $\mathrm{C}$ were made with water-cement ratios of $0.3,0.4$ and 0.5 , respectively (See Table 1), and the superplasticizer was adjusted to keep the same flow of the paste. In order to study the effect of different concentrations of fine ag- gregate on the elastic modulus and total void of mortar, six volume fractions (volume of fine aggregate/volume of cement-based materials, $a / t=0 ., 0.05,0.1,0.2,0.3$, and 0.4 ) of fine aggregate were considered in the mix proportions. Notation for the specimens is that the first letter indicates $w / c$ ratio $\mathrm{A}, \mathrm{B}$, and $\mathrm{C}$ and the number is the volume fraction of aggregate.

Cylindrical specimens $(\phi 100 \times 200 \mathrm{~mm})$ were cast and cured in water. At the age of 28 days, all cylinders were ground and polished before testing to achieve smooth end surface. For determining the elastic moduli of the mortars, two axial LVDTs (linear variable differential transducers) were mounted on opposing sides of specimen to measure the compressive strains. The compressive test was conducted using a 1000-KN universal testing machine according to the specification of ASTM C 469-81 (ASTM Test Method for Static Modulus of Elasticity and Poisson's Ratio of Concrete in Compression). The load was applied at a constant rate within the range of $0.14 \sim 0.34 \mathrm{MPa} / \mathrm{sec}$. Continuous measurements were recorded to obtain the stress/strain curves and the secant modulus was determined from the stress/strain curves.

\section{RESULTS AND DISCUSSIONS}

In this study, the mortar was considered as a threephase (cement paste, aggregate, and void) composite materials, the shape of fine aggregate and total void 
Table 2. Elastic modulus of mortar, measured and calculated results

\begin{tabular}{|c|c|c|c|c|}
\hline \multirow[b]{2}{*}{ Notation } & \multirow[b]{2}{*}{$\mathrm{w} / \mathrm{c}$} & \multicolumn{2}{|c|}{ Elastic modulus, (GPa) } & \multirow[b]{2}{*}{$\frac{\bar{E}-E_{c}}{E_{c}} \times 100(\%)$} \\
\hline & & $\begin{array}{c}{ }^{*} E_{c} \\
\text { (Experimental) }\end{array}$ & $\begin{array}{c}\bar{E} \\
\text { (Theoretical) }\end{array}$ & \\
\hline A00 & & 22.41 & & \\
\hline A05 & & 23.65 & 23.71 & 0.25 \\
\hline A10 & 0.3 & 25.01 & 25.08 & 0.28 \\
\hline A20 & & 27.57 & 28.09 & 1.89 \\
\hline A30 & & 30.40 & 31.50 & 3.62 \\
\hline A40 & & 34.14 & 35.41 & 3.72 \\
\hline B00 & & 17.92 & & \\
\hline B05 & & 19.00 & 19.10 & 0.53 \\
\hline $\mathrm{B} 10$ & 0.4 & 20.16 & 20.35 & 0.94 \\
\hline $\mathrm{B} 20$ & & 21.90 & 23.13 & 5.63 \\
\hline B30 & & 24.22 & 26.34 & 8.75 \\
\hline B40 & & 26.09 & 30.09 & 15.32 \\
\hline $\mathrm{C} 00$ & & 17.08 & & \\
\hline $\mathrm{C} 05$ & & 17.92 & 18.23 & 1.73 \\
\hline $\mathrm{C} 10$ & 0.5 & 19.18 & 19.45 & 1.40 \\
\hline $\mathrm{C} 20$ & & 20.59 & 22.17 & 7.66 \\
\hline $\mathrm{C} 30$ & & 22.92 & 25.32 & 10.48 \\
\hline $\mathrm{C} 40$ & & 23.96 & 29.03 & 21.14 \\
\hline
\end{tabular}

*Average of five specimens

were modeled as sphere and fine aggregate and void were considered as spherical shape. The inclusions (fine aggregate and void) were considered as randomly embedded in the cement paste. Two-stage calculation was performed. Firstly, the estimated elastic modulus of fine aggregate was calculated by two-phase composite model (cement paste and fine aggregate) for the mortar.. Secondly, double inclusion model for a threephase composite (cement paste, fine aggregate, and void) was used to calculate the volume of void for the mortar with various $w / c$ ratios.

\section{Elastic modulus of fine aggregate}

By considering the mortar $(w / c=0.3)$ as a twophase material (cement paste and aggregate), Yang et al. [17] proposed a theoretical model based on MoriTanaka theory and Eshelby's method in which the stress disturbance due to inhomogeneities under the applied compressive stress. The inhomogeneities can be simulated by the eigenstress caused by the fictitious misfit strain. The fictitious misfit strain (eigenstrain) was introduced to simulate the inhomogeneity effect. The model (single inclusion model) can approximate the average elastic relationships of the cement-based materials with spherical inhomogeneities. In the pervious work, the overall average elastic moduli tensor of cement-based materials $\underset{\sim}{C}$ was given by [17]

$$
\begin{aligned}
\bar{\sim}= & \left\{\underset{\sim}{C^{-1}+f}\left[\left\{(1-f)\left(C^{*}-\underset{\sim}{C}\right) S-f\left(\underset{\sim}{C}-{\underset{\sim}{*}}^{*}\right)+\underset{\sim}{C}\right\}^{-1}\right]^{-1}\right. \\
& \left.\left(\underset{\sim}{C}-C^{*}\right) C^{-1}\right\},
\end{aligned}
$$

where $\underset{\sim}{C}$ and $\underset{\sim}{C}$ are the elastic moduli tensor of matrix and inclusion, respectively. $f$ is the volume fraction of inclusion, and $\underset{\sim}{S}$ is the Eshelby's tensor. The Eshelby tensor is a function of the geometry of the inclusion and Poisson's ratio of the matrix (see Appendix A).

For mix A, the elastic moduli of cement pastes and mortars were obtained directly from the test results and presented in Table 2. For the computation of the elastic modulus tensor of the matrix and the mortar, the Poisson's ratio of cement paste and aggregate was assumed to be 0.2 and 0.3 [18], respectively. Equation (1) was used to calculate the elastic modulus of the fine aggregate based on single inclusion model. The average elastic modulus of fine aggregate $\left(E_{a}\right)$ is $80 \mathrm{GPa}$. Figure 1 shows the experimental results and calculated results when the mortar is considered as a two-phase (cement paste and aggregate) composite. 


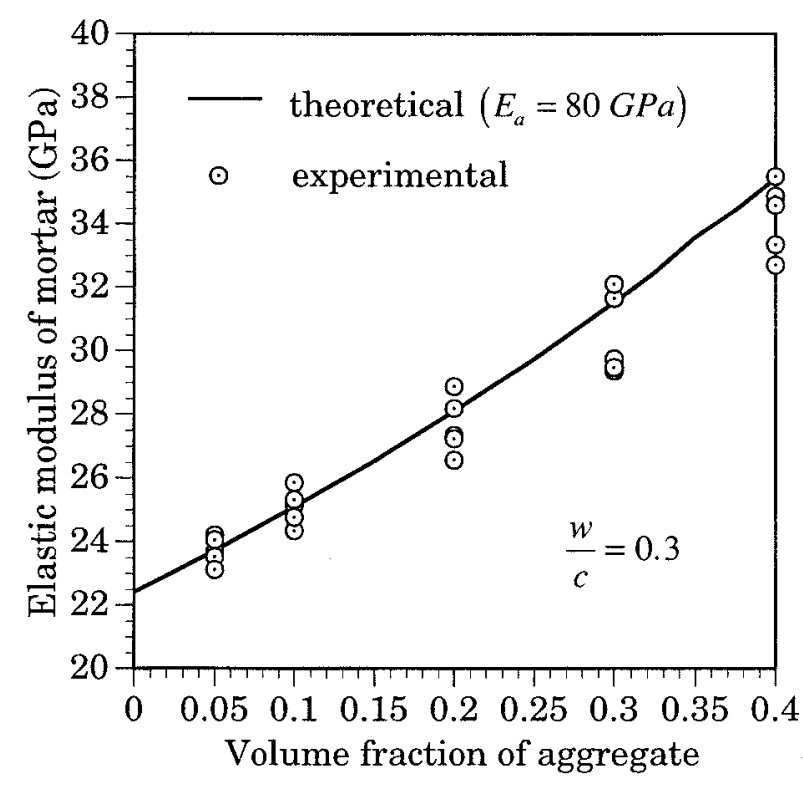

Fig. 1. Elastic modulus vs. volume fraction curve (two-phase model).

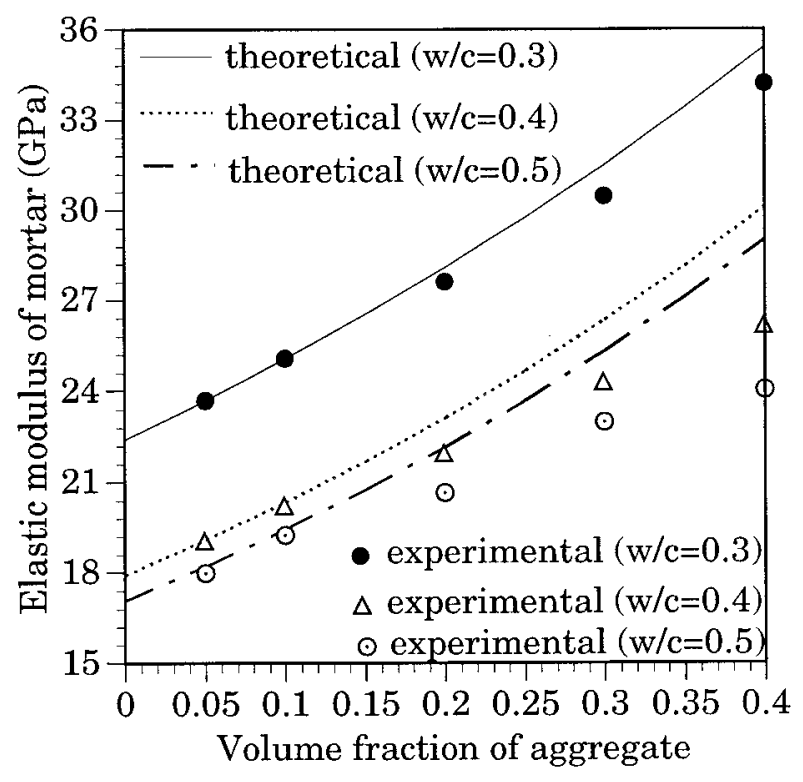

Fig. 2. Elastic modulus vs. volume fraction curves (two-phase model).

\section{Two-phase composite (cement paste and aggregate)}

For calculation the overall elastic modulus of two phase composite, the volume fraction of void is considered to be 0 and the aforementioned elastic properties of cement paste and aggregate are applied to obtain the elastic moduli of mortar from eqn (1).

Figure 2 shows the experimental results and the calculated results when the mortar is considered as a two-phase (cement paste and aggregate) composite.

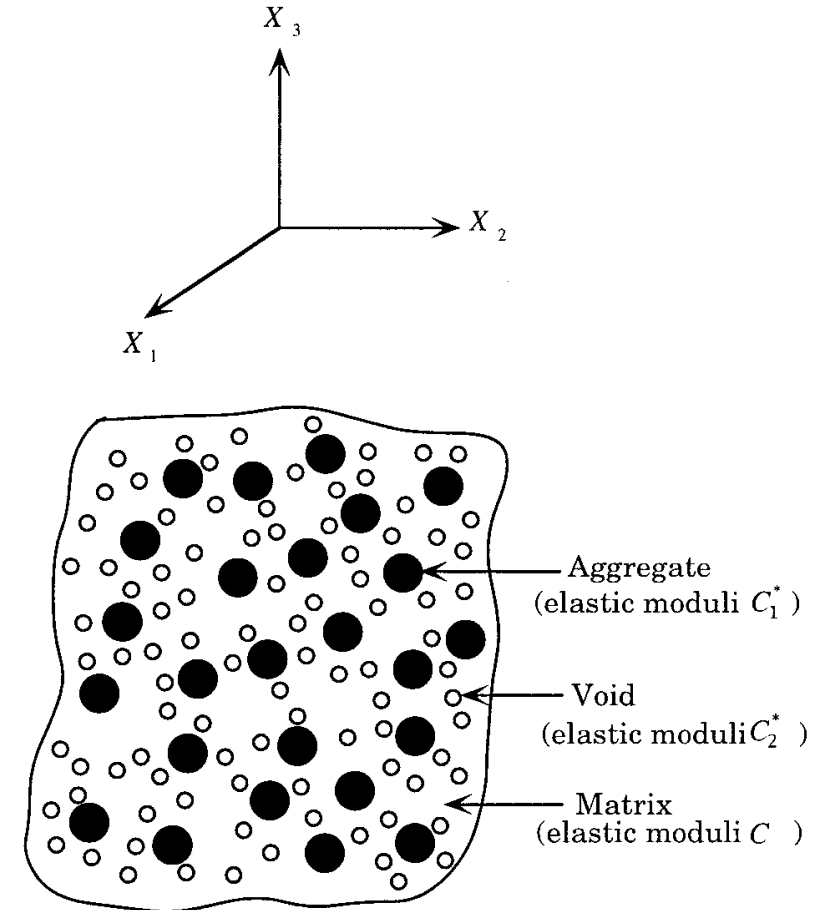

Fig. 3. Aggregates and voids are modeled as spherical shape which embedded in matrix.

The corresponding experimental results are also illustrated in the figure. The figure illustrates the relationship between volume fraction of aggregate and elastic modulus of mortar. It can be seen from the figure that increase in aggregate volume fraction improve the mortar elastic modulus. For mix B and C, experimental results are less than the calculated results which was obtained based on a two-phase model. The difference between the experimental data and the theoretical results, because more significant when higher aggregate volume fraction is used. It appears that the volume fraction of aggregate increases, the void structure (third phase) affects the elastic modulus of mortar is more prominent. Therefore, it is reasonable to consider the third phase (void) in the analytical process.

Three-phase composite (cement paste, aggregate, and void)

Consider two types of spherical inhomogeneities, $\Omega_{\alpha}(\alpha=1,2)$ randomly embedded in an infinite matrix with the elasticities $\underset{\sim}{C}$. The elasticities of $\Omega_{\alpha}$ are $C_{1}^{*}$ and $C_{2}^{*}$, respectively, and the volume fraction of $\Omega_{\alpha}$ are $f_{1}$ and $f_{2}$. the stress disturbance in the applied compressive stress, $\sigma^{o}$, due to inhomogeneities can be simulated by the eigenstress caused by the two types fictitious misfit strain (Fig. 3). In this study, the fictitious misfit 
Table 3. The elastic modulus and volume fraction of components

\begin{tabular}{|c|c|c|c|c|c|}
\hline \multirow[b]{2}{*}{ National } & \multicolumn{3}{|c|}{ Elastic modulus, (GPa) } & \multicolumn{2}{|c|}{ Volume fraction, $(\%)$} \\
\hline & $\begin{array}{c}\text { Cement } \\
\text { paste }\end{array}$ & Aggregate & *Mortar & Aggregate & *Total void \\
\hline B05 & & & 19.00 & 5 & 0.26 \\
\hline B10 & & & 20.16 & 10 & 0.48 \\
\hline B20 & 17.92 & 80 & 21.90 & 20 & 2.70 \\
\hline B30 & & & 24.22 & 30 & 4.10 \\
\hline B40 & & & 26.09 & 40 & 6.80 \\
\hline $\mathrm{C} 05$ & & & 17.92 & 5 & 0.82 \\
\hline $\mathrm{C} 10$ & & & 19.18 & 10 & 0.67 \\
\hline $\mathrm{C} 20$ & 17.08 & 80 & 20.59 & 20 & 3.70 \\
\hline $\mathrm{C} 30$ & & & 22.92 & 30 & 4.90 \\
\hline $\mathrm{C} 40$ & & & 23.96 & 40 & 9.20 \\
\hline
\end{tabular}

*Average of five specimens

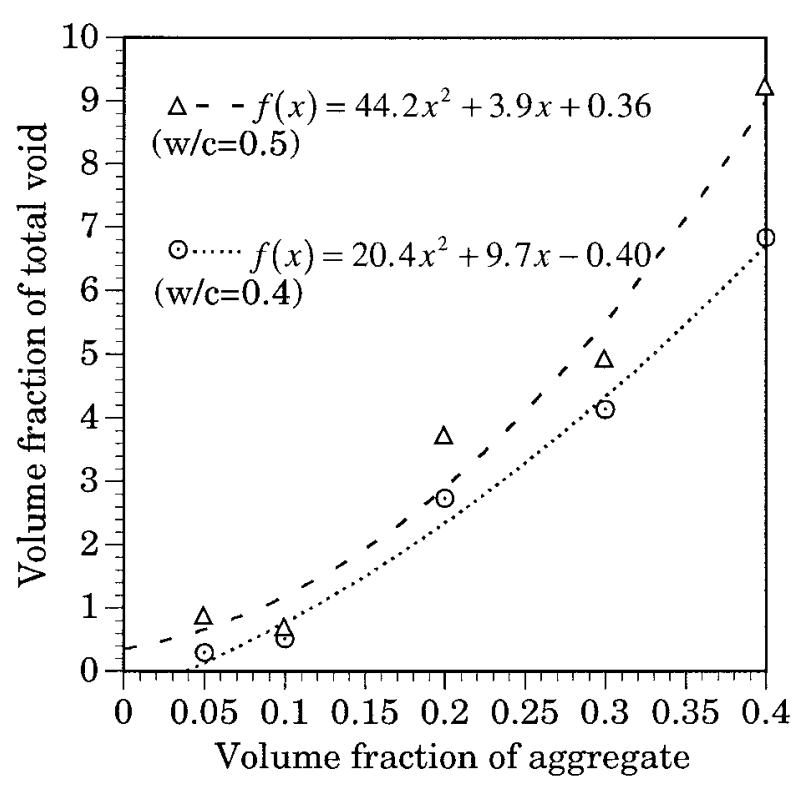

Fig. 4. Volume fraction of total void vs. aggregate curves.

strains (eigenstrain), $\varepsilon_{1}^{*}$ and $\varepsilon_{2}^{*}$, were introduced to simulate the inhomogeneity effect. By use of the equivalent inclusion method [16] and represent Mori-Tanaka theory [14], the average stress $\sigma^{o}+\left\langle\sigma^{\Omega_{1}}\right\rangle$ in the $\Omega_{1}$ and $\sigma^{o}+\left\langle\sigma^{\Omega_{2}}\right\rangle$ in the $\Omega_{2}$ can be as follows

$$
\begin{aligned}
& \underline{\sigma}^{o}+\left\langle\widetilde{\sigma}^{\Omega_{1}}\right\rangle=\underset{\sim}{C}\left\{{\underset{\sim}{C}}^{-1}\left(\underline{\sigma}^{o}+\left\langle\widetilde{\sigma}^{M}\right\rangle\right)+\underset{\sim}{S_{1}}\left\langle{\underset{\sim}{1}}_{1}^{*}\right\rangle-\left\langle{\underset{\sim}{2}}_{2}^{*}\right\rangle\right\} \\
& =\mathscr{\sim}_{1}^{*}\left\{\boldsymbol{\sim}^{-1}\left(\sigma^{o}+\left\langle\sigma^{M}\right\rangle\right)+S_{1}\left\langle\varepsilon_{1}^{*}\right\rangle\right\}, \\
& \sigma^{o}+\left\langle\sigma^{\Omega_{2}}\right\rangle=\underset{\sim}{C}\left\{\stackrel{C}{ }^{-1}\left(\sigma^{o}+\left\langle\sigma^{M}\right\rangle\right)+{\underset{\sim}{2}}_{2}\left\langle\varepsilon_{2}^{*}\right\rangle-\left\langle\varepsilon_{2}^{*}\right\rangle\right\} \\
& =C_{2}^{*}\left\{C^{-1}\left(\sigma^{o}+\left\langle\sigma^{M}\right\rangle\right)+S_{2}\left\langle\varepsilon_{2}^{*}\right\rangle\right\},
\end{aligned}
$$

where " \langle\rangle " is the notation for the average and $\sigma^{o}+\left\langle\sigma^{M}\right\rangle$ is the average stress in the matrix. The Eshelby tensors, $S_{1}$ and $S_{2}$ (see Appendix A) are the ellipsoidal inclusion when it isolately exists in an infinite homogeneous medium.

The average eigenstrains and the average stress of inclusions are evaluated. Therefore, the overall elasticity tensor $\bar{\sim}$ is given by [18]

$$
\bar{\sim}=\left({\underset{\sim}{C}}^{-1}+f_{1} \alpha+f_{2} \beta\right)^{-1} .
$$

$\alpha$ and $\beta$ are shown in Appendix B.

In this study, for calculation the overall elastic modulus of three-phase cement-based materials with void, the elastic modulus and Poison's ratio of void were assumed to be 0 . The aforementioned elastic modulus and Poisson's ratio of cement paste were used. The overall elastic modulus of three-phase cement-based materials were calculated from eqn. (4). For computing the volume fraction of total void, substitute elastic moduli tensor of aggregate $C_{1}^{*}$, elastic moduli tensor of void $C_{2}^{*}$, elastic moduli tensor of cement paste $\underset{\sim}{C}$, volume fraction of aggregate $f_{1}$, the average elastic moduli tensor of mortar $\bar{C}$, Eshelby tensor for aggregate $S_{1}$ (see Appendix A), and Eshelby tensor for void $S_{2}$ into eqn (4), the volume fraction of total void $f_{2}$ can be obtained. The calculated volume fractions of total void for mix $\mathrm{B}$ and $\mathrm{C}$ are shown in Table 3 . It shows that the volume fraction of void increases as water cement ratio increases. Figure 4 illustrates the relationship between volume fraction of aggregate and volume fraction of void. It also appears that the volume fraction of void increases as volume fraction of aggregate increases.

\section{CONCLUSIONS}

The elastic modulus of cement-based composite 
are influenced by the elastic properties and volume fraction of the matrix, aggregate, and void. The elastic modulus of cement-based composite increases with increasing volume fraction of aggregate. The volume of void depends on the volume fraction of aggregate and water cement ratio. When higher volume fraction of aggregate is used in the mix, the elastic modulus of the composite should be computed by introducing a third phase (void) into the composite. For the mix with lower volume fraction of aggregate, because the volume of void is relatively small in comparison with the volume of other components, two-phase approach is appropriate for evaluating the elastic moduli of the composites. It seems that Double-Inclusion method and Mori-Tanaka theory can be properly used to estimate the elastic moduli of mortar consisting of three different phases of cement paste, aggregate and void.

\section{ACKNOWLEDGMENT}

The support of NSC Contract No. NSC 88-2221-E019-007 is gratefully appreciated.

\section{REFERENCES}

1. Mehta, P.K., Concrete Structure, Properties, and Materials, Prentice-Hall, New Jersey, pp. 26-27 (1986).

2. Manning, D.G. and Hope, B.B., "The Effect of Porosity on the Compressive Strength and Elastic Modulus of Polymer Impregnated Concrete," Cement and Concrete Research, Vol. 1, pp. 631-644 (1971).

3. Hasselman, D.P.H., Gebauer, J. and Manson, J.A., "Elastic Behavior of Polymer-Impregnated Porous Ceramics," J. of The American Ceramic Society, Vol. 55, No. 12, pp. 588-591 (1972).

4. Beaudoin, J.J., Feldman, R.F. and Tumidajski, P.J., "Pore Structure of Hardened Portland Cement Pastes and Its Influence on Properties," Advn. Cem. Bas. Mat., Vol. 1, pp. 224-236 (1994).

5. Zimmerman, R. W., King, M. S. and Monteiro, P. J. M., "The Elastic Moduli of Mortar as a Porous-Granular Material," Cement and Concrete Research, Vol. 16, pp. 239-245 (1986).

6. Hirsch, T.J., "Modulus of Elasticity of Concrete Affected by Elastic Moduli of Cement Paste Matrix and Aggregate," ACI Journal, pp. 427-451, (1962).

7. Aïtcin, P.C. and Mehta, P.K., "Effect of Coarse-aggregate Characteristics on Mechanical Properties of Highstrength Concrete," ACI Materials Journal, Vol. 87, No. 2, pp. 103-107 (1990).

8. Baalbaki, W., Benmokrane, B., Chaallal, O. and Aïtcin, P.C., "Influence of Coarse Aggregate on Elastic Properties of High-performance Concrete," ACI Materials Journal, Vol. 88, No. 5, pp. $499-503$ (1991).
9. Stock, A.F., Hannant, D.J. and Wiliams, R.I.T., "The Effect of Aggregate Concentration upon the Strength and Modulus of Elasticity of Concrete," Magazine of Concrete Research, Vol. 31, No. 109, pp. 225-234 (1979).

10. Voigt, W., "Über die B eziehung zwischen den beiden Elastizität Skonst Anten Isotroper KÖrper," Wied. Ann., Vol. 38 pp. 573-587 (1889).

11. Reuss, A., "Berechnung der Fliessgrenze von Mischkristallen auf Grund der Plastizität Sbedingung für Einkristalle," Z. Angew. Math. Mech., Vol. 9, pp. 4958 (1929).

12. Hashin, Z. and Shtrikman, S., "On Some Variational Principles in Anisotropic and Nonhomogeneous Elasticity," Journal of the Mechanics and Physics of Solids, Vol. 10, pp. 335-343 (1962).

13. Hansen, T.C., "Strength Elasticity, and Creep as Related to the Internal Structure of Concrete," Chemistry of Cement, Proceedings of the Fourth International Symposium, Monograph 43, Vol. 2, pp. 709-723 (1960).

14. Mori, T. and Tanaka, K., "Average Stress in Matrix and Average Energy of Materials with Misfitting Inclusions," Acta Metallurgica, Vol. 21, pp. 571-574 (1973).

15. Eshelby, J.D., "The Determination of the Elastic Field of an Ellipsoidal Inclusion, and Related Problems," Proceeding Royal Society, A241, pp. 376-396 (1957).

16. Mura, T. "Micromechanics of Defects in Solids," Second Revised Edition, Martinus Nijhoff Publishers, (1987).

17. Yang, C.C., Huang, R., Yeih, W., and Chang, J.J., "Theoretical Approximate Elastic Moduli of Concrete Material," The Chinese J. of Mechanics, Vol. 11, pp. 4753 (1995).

18. Yang, C.C. and Huang, R., "Double Inclusion Model for Approximate Elastic Moduli of Concrete Material," Cement and Concrete Research, Vol. 26, pp. 83-91 (1996).

\section{APPENDIX A}

The Eshelby's tensor $\underset{\sim}{S}$ for sphere inclusion is listed below [16].

$$
\begin{aligned}
& S_{1111}=S_{2222}=S_{3333}=\frac{7-5 v}{15(1-v)} . \\
& S_{1122}=S_{2233}=S_{3311}=S_{1133}=S_{2211}=S_{3322}=\frac{5 v-1}{15(1-v)} . \\
& S_{1212}=S_{2323}=S_{3131}=\frac{4-5 v}{15(1-v)} .
\end{aligned}
$$

\section{APPENDIX B}

The calculation of parameters $\alpha$ and $\beta$

$A=\left[\left(1-f_{1}\right) C+f_{1} C_{1}^{*}\right]\left(S_{1}-I\right)-C_{1}^{*} S_{1}$ 


$$
\begin{aligned}
B= & {\left[\left(1-f_{2}\right) C+f_{2} C_{2}^{*}\right]\left(S_{2}-I\right)-C_{2}^{*} S_{2} } \\
M= & \left(C_{1}^{*}-C\right)\left(S_{2}-I\right) \\
N= & \left(C_{2}^{*}-C\right)\left(S_{1}-I\right) \\
\left\langle\varepsilon_{1}^{*}\right\rangle= & -\left(I-f_{1} f_{2} A^{-1} M B^{-1} N\right)^{-1} A^{-1}\left[f_{2} M B^{-1}\left(C_{2}^{*} C-I\right)\right. \\
& \left.+\left(C_{1}^{*} C-I\right)\right] \sigma^{o} \\
& =\alpha \sigma^{o} \\
\left\langle\varepsilon_{2}^{*}\right\rangle & =B^{-1}\left\{f_{1} N\left(I-f_{1} f_{2} A^{-1} M B^{-1} N\right)^{-1} A^{-1}\right. \\
& {\left.\left[f_{2} M B^{-1}\left(C_{2}^{*} C-I\right)-\left(C_{1}^{*} C-I\right)\right]+\left(C_{2}^{*} C-I\right)\right\} \sigma^{o} } \\
& =\beta \sigma^{o}
\end{aligned}
$$

\section{細骨材體積比對水泥質材料孔隙含 量及彈性模數之影響}

卓世偉楊仲家

國立台灣海洋大學材料工程研究所

$$
\text { 黄 然 }
$$

國立台灣海洋大學河海工程系所

$$
\text { 摘 要 }
$$

本研究主要探討骨材含量對水泥砂漿中孔隙含 量及彈性模數之影響。研究中以六種不同細骨材體積 比（細骨材體積／水泥砂漿體積＝0、0.05、0.1、 $0.2 、 0.3 、$ 及 0.4$)$ 與三種不同水灰比 $(0.3 、 0.4$ 、及 $0.5)$ 之水泥砂漿圆柱試體進行實驗, 理論模式方 面, 將水泥砂漿視爲三相複合材料 (水泥漿體、細骨 材、及孔吵）。應用隻置入物理論模式配合複合材料 各組成物材料性質與含量之實驗值, 推估不同細骨材 體積比及不同水灰比之水泥砂漿中的孔隙體積。 